\title{
On the Cultivation of Students' Speculative Thinking Ability in Foreign Language Teaching
}

\author{
Cui Jingjing \\ Jinlin Business and Technology College \\ P.R. China, 130062 \\ 107851252@qq.com
}

\begin{abstract}
This paper is based on the status of speculative ability both at home and abroad and the importance of thinking ability of foreign language teaching to explore on the cultivation of students' thinking ability in foreign language teaching. The cultivation of speculative ability promotes the application students' foreign language comprehensive ability and humanistic quality, especially the high quality way of thinking. It accelerates students' deep understanding which can enhance students to read, think and debate that combined with thinking and improve the effectiveness of foreign language teaching.
\end{abstract}

Keywords—speculative ability, foreign language teaching, inquiry

\section{INTRODUCTION}

The term "Critical" is derived from the two Greek word "kriticos" and "Criterion", which means "the ability to ask, understand, analyze and judge". [1]In terms of etymology, the ability to speculate is based on the identification of the appropriate assessment criteria. John Dewey called it "Reflective Thinking" and Robert Ennis described it as "a personal judgment of the authenticity, accuracy, nature and value of what is being learned, so as to what to do and believe what to make a reasonable decision-making ability.” [2] The Delphi Report (1990) defines it as a purposeful, self-regulating judgment process that results in explanations, analyzes, evaluations, inferences, and evidence, concepts, Methods, standards or contexts [3]. Although, experts and scholars from the pedagogy, philosophy, psychology and other disciplinary perspectives on the ability to speculate in-depth discussion and definition, they did not leave criticism, reflection, reflection and other characteristics of nature. Edward Glaser used the term "Critical Thinking" in his 1941 book [4], which is also widely used in the field of research. China's scholars will be translated as: "critical thinking", "critical thinking", "critical thinking", "thinking ability" and "high-level thinking". In the 1980s, the United States and the United Kingdom and other developed countries began to explore students thinking ability, including the ability to define the speculative, measuring tools and training strategies. At the beginning of this century, with the deepening of China's education reform, education reform and development of the core objectives are constantly adjusted one of the important goals is to develop students to have the courage to explore the innovative spirit and good problemsolving practice ability, which highlights the importance of cultivating students' speculative thinking ability. Due to the particularity of foreign language learning, the traditional teaching methods of our country, the setting of foreign language teaching courses and the evaluation methods, the speculative ability of foreign language learners in China needs to be greatly improved. The development of foreign language learners' speculative thinking ability will contribute to the development of comprehensive quality comprehensive English talents, which is in full compliance with the requirements of the new foreign language teaching syllabus. The development of foreign language learners' thinking ability involves many factors such as teachers, students, teaching and environment. Therefore, education researchers should explore a set of characteristics which are suitable for foreign language learners to meet the needs of English majors, promote foreign language learners in all directions and enhance the comprehensive strategy of the Development of speculative.

The development of speculative thinking ability is an important goal of higher education, especially foreign language learners should master English skills, meanwhile, should have the ability to speculate and improve the quality of human accomplishment and quality. The Teaching Guideline Committee of College Foreign Language Teaching Reform in 2000 pointed out that: "21st century, China's higher education institutions of higher learning English professionals should have a solid basic skills, broad knowledge, a certain correlation professional knowledge, strong ability and high quality. That is to say, we should lay a solid foundation of English language skills and a solid grasp of English professional knowledge under the premise of broadening the humanities knowledge and scientific and technological knowledge. We should master basic knowledge of the relevant professional after graduation and focus on cultivating the ability to acquire knowledge, independent thinking and innovation ability to improve the ideological and moral quality, cultural quality and psychological quality. "[5] Higher education should be committed to developing students' thinking skills, rather than to teach students knowledge for the purpose and orientation. As Brian Roper points out, higher education should develop students' abstract thinking, logical thinking, effective reasoning, and evidence-based evaluation [6].Thus, it plays a significant role to improve the ability of students to speculate on the cultivation of innovative talents. Students should have the ability to speculate, analyze and judge, so as to bring innovative ideas. If the teaching objectives, teaching content and teaching methods carry out the necessary reforms, students will impart knowledge to achieve effective training students thinking ability of purpose. 
Speculative ability has become a high-quality talent and necessary ability to improve the effective learning of students an important strategy. The combination of language, content and four sides will improve the classroom efficiency of foreign language teaching; ultimately, improve the students' thinking ability.

\section{DOMESTIC AND INTERNATIONAL RESEARCH ON THE STATUS of SPECULATIVE ABILITY}

At abroad, the study of speculative thinking ability in the past two or three decades has been rapid development. Since 1990's, the ability to speculative thesis and academic works have been rapidly increased. According to Luo Qingxu's report (Luo Qingxu, 2002), from 1970 to 2000,there are 158 papers in the United States in psychology and pedagogy around the theme of the "high-level thinking ability"; there are a total of 114 collections and "High-level thinking ability" related works collected by the United States Library of Congress and it published numerous papers. In teaching, the US government began university education goals in 1993. Britain and other Western countries have followed. So far, it has formed a relatively perfect speculative ability teaching evaluation system. Interiorly, it is rare to study academic papers in the field of speculative ability. Professor Yang Qing in the book of "Introduction to Psychology," explores that we can regard the speculative nature of thinking as a quality of a preliminary study. Chen Qi and others in his editor book of "Contemporary Educational Psychology" which refines the ability to speculate as a new trend in educational psychology with a section of the study of foreign speculative ability and preliminary introduction. In terms of research papers, the present research on the speculative power is mainly focused on two aspects: (1) a general introduction or review of some aspects of foreign speculative ability (Luo Qingxu, 2000, 2001, 2002; Liang Hongjun, 2006); (2) the analysis of the status of students thinking ability (Huang Yuan Shen, 1998, 2010). It can be seen from the analysis of the status quo of the study of speculative ability both at home and abroad. Compared with foreign countries, they have formed a relatively perfect teaching and evaluation system of speculative ability. The study of speculative ability is still in bloom, which are lack necessary and systematic research. And it is lacking in the research on the thinking ability of foreign language students. Still, it is lacking in the analysis stage of the cause of absent reasoning ability. On this basis, Wen Qiufang (2008) puts forward the hierarchical theoretical model of high-level thinking ability of postgraduates of foreign languages (Wen Qiufang translated the term "critical thinking skills" as "highlevel Thinking ability ", which takes into account the Cultural Revolution, the" critique "excessive use of the term, which also hurt the" critical thinking "of the word, so that people tend to have negative associations, fear of being misinterpreted).[7] The so-called speculative thinking ability is the ability to think and analyze: which refers to thinking, analysis, reasoning, judgments and other thinking activities; analysis refers to the situation of things, categories, such as the identification of the analysis. In essence, speculative thinking ability is an abstract thinking ability at first. In the past century, Western countries have attached great importance to the research of students' thinking ability. In the 1950s, American educator Bloom proposed the classification of educational goals: knowledge, understanding, application, analysis, synthesis, evaluation, of which the latter three are recognized as high-level thinking ability.

Since the 1980s, speculative research in the West is in full swing, the theoretical system is increasingly mature. For the definition of speculative power, the scholars are also wise to see the wisdom of the beholder, which is typical of the American Philosophical Society, "Delphi" project group proposed by the definition of speculative ability while revealing the essence of speculative thinking ability: evaluation, reasoning, explanation and self-regulation, which analysis, reasoning and evaluation is the core skills. There are many research results in relating to the ability of speculation: the American philosopher Richard Paul and the educational psychologist Linda Elder put forward the three-dimensional structure model which is based on the demand of teaching. First, the speculative thinking element includes purpose, problem and information, definition, assumption, horizon reasoning and enlightenment; Second, criterion includes accuracy, importance, relevance, integrity, logic, fairness, breadth and depth; Third, the intellectual characteristics, including humility, self-confidence, perseverance, independence, self-confidence, integrity, compassion, courage and impartiality. Scholars have different views on how to cultivate students' ability of speculation: some scholars believe that different disciplines have different disciplinary logic. We should emphasize the discipline of speculative ability, different disciplines; some scholars further emphasize the practical discipline teaching which are integrated into the cultivation of the ability to speculate to promote students to actively thinking and take the initiative to learn; the other scholars believe that we should be set up a special thinking training courses and develop the ability to speculate as a foreign language learners. It is particularly important to integrate the speculative thinking into the specialized disciplines of speculative teaching.

\section{THE IMPORTANCE OF THINKING ABILITY IN FOREIGN LANGUAGE TEACHING STUDENTS}

College foreign language education has been criticized. "Ineffective", "dumb English", "deaf English" is the biggest impression of college English education on the academic community. In recent years, thanks to the reform of college English teaching, the use of modern information technology, such as network classrooms and media autonomous learning centers, has played a significant role in improving college English teaching. Students can express themselves more fluently in English. However, the problem, such as lacking of deep thought, language cave, substance and speculation, is more serious in the foreign language students' language expression. Throughout the college foreign language teaching, we can sum up that students use the network for autonomous learning to focus on polishing the language skills of students, rather than the lack of discipline training and humanities education.

Although the network course provides students with more information sources, lacking of correct guidance will also benefit their ability to develop. According to the speculative 
model, the cultivation of reading and listening skills related to the basic reading materials can be classified as cognitive and comprehension in the cognitive stage. Instead, the oral and writing courses can cultivate students' application to a certain extent. We should train students' ability of evaluation and creation and students need to think and evaluate some specific topics or popular events on the basis of the existing language. They can use the basic skills of language to develop a way of long-term learning to create new languages phenomenon. Therefore, a reasonable curriculum design will be beneficial to the development of students' cognitive ability, especially the analysis, evaluation and creation of advanced cognitive ability, and then improve their speculative ability. Firstly, we should explore the "basic skills to train English on the basis for encyclopedic knowledge to teach as the goal of" training model, and emphasis on humanities and general education. Encyclopedia of knowledge is like learning different nodes in the network, you can form a system of network and affecting students. Encyclopedia of knowledge transfer the accumulation to help students develop from multiple angles to think and analyze the problem. And from a different point of view, students should participate in the evaluation and out of the box. Secondly, we should make full use of interactive learning environment which brought about the network learning environment, such as micro blogging, QQ, We Chat and other network service platform to deeoen learning; in the course of the Internet platform, we join the hot topic and invite students to participate in Foreign Language Discuss and write a text report. Students use the language knowledge what they have learned to analyze and discuss the latest hot events and develop their analytical skills. Thirdly, in the specific foreign language teaching, students need to focus on thinking ability to develop design teaching tasks, increase student, student and teacher interaction, and provide students with the selection, reading, discussion of curriculum resources platform. Through the exchange of activities for students, it can provide opportunities to show the ability to speculate and build teacher evaluation, peer assessment, student self-evaluation of the comprehensive evaluation system so as to encourage students to write a reflection log. All these will help the students to cultivate the students' speculative thinking ability, at the same time, students will realize the goal of cultivating the speculative thinking ability, and also need the high-quality learning environment.

\section{CONCLUSION}

Language is not only the carrier of culture, the tool of communication, but also the thinking tool. Since the reform and opening up, with the large amount of investment in foreign language training and the continuous deepening of foreign language teaching reform, foreign language teaching in China has achieved remarkable achievements. We have cultivated a large number of foreign language professionals in line with social development needs. However, with the continuous development of social economy, foreign language professionals only as a carrier of culture and communication tools have been far from meeting the needs of society. Now the foreign language talents need to have independent thinking and comprehensive analysis of the problem. To cultivate this ability of students, it is bound to require foreign language teaching practitioners to change the teaching concept, master the language as the theoretical basis of thinking tools, in the classroom practice, we should focus on students' speculative thinking ability. As an important aspect of the overall quality of foreign language students, the ability of speculation should be highly valued by our foreign language teaching and learning staff. As a long - term role, people benefit from the infinite intelligence resources; it is the basis of social rationality and democracy. Quality education is the essence of the University. To improve students' ability of speculation is a long-term effort to system engineering, we need foreign language teaching workers continue to explore, long-term efforts.

\section{REFERENCES}

[1] Paul, R. \& L. Elder. Critical Thinking: Learn the Tools the Best Thinkers Use[M]. New Jersey: Pearson Prentice Hall, 2006.

[2] Ennis, R. Critical Thinking: A Streamlined Conception [J].Teaching Philosophy, 1991, (1): 22-25.

[3] Facione, P. A. \& N. C. Facione. Holistic Critical Thinking Scoring Rubric [M].California: California Academic Press, 1994.

[4] Glaser, E. M. An Experiment in the Development of Critical Thinking [M].New York: Teacher's College, Columbia University, 1941.

[5] College of Foreign Language Teaching Steering Committee English Group. College English Teaching Syllabus [S]. Beijing: Foreign Language Teaching and Research Press, 2000.

[6] Wen Qiufang, et al. Construction of the theoretical framework of the proficiency of Chinese foreign language students [J] Foreign Language, 2009, (1): 37-43.

[7] Wen Qiufang .Discussion on the Cultivation of Postgraduates' Highlevel Thinking Ability in Foreign Language Majors [J] .Journal of Postgraduates and Education, 2008, (10): 29-34. 